\title{
Adaptation of spring-sown chickpea to the Mediterranean basin. I. Response to moisture supply
}

\author{
S.N. Silim and M.C. Saxena

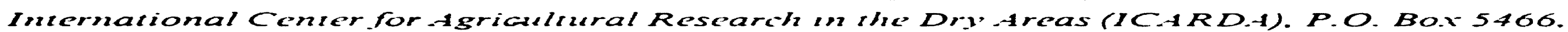 \\ -1leppo. Syricia \\ (Accepled 23 February 1993 )
}

\section{ABSTRACT}

Chickpca is grown in spring as a rainfed crop in West Asia and North Africa (W. NA) regionsin areas with mean annual rainfall of not less than too mm but where the rainfallamountand distribulion are highly variable. We hypothesized that for W. AN. A. the bestadapted culivars should produce high yields in years with low rainfalland be responsive io moisturesupply in years with high rainfall siudies were therefore conducted to determine whether there is genetic wariability in response to moisture supply and if so to develop breeding strategies that suppor our hypothesis. chickpea cultivars of diverse origin were grown under a soll moisture gradient using a line-source sprinkler irrigat vars of diverse origin were grown under a soll moisture gradient using a line-source sprinkier irrigas7. rainfall (359 mm) was similar io the long-term average but lenperatures in the March-May s7, rainfall (359 mm) was similar to the long-term average but lenperatures in the March-May

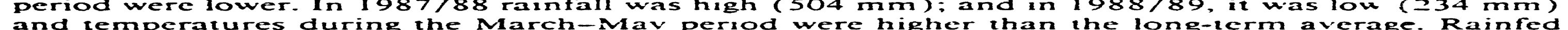
and temperatures during the March-May period were higher than ihe long-iermaverage. Rainfed mean grain yields were 0.984 tha in $1986 / 87$. 1. O99 /ha in $1987 / 88$ and 0.187 /ha in $1988 / 89$.

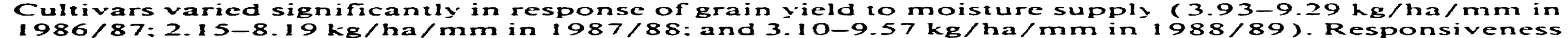
$1986 / 87: 2.15-8.19 \mathrm{~kg} / \mathrm{ha} / \mathrm{mm}$ in $1987 / 88$ and $3.10-9.57 \mathrm{~kg} / \mathrm{ha} / \mathrm{mm}$ in $1988 / 89$ ). Responsiveness lation between the responsiveness to moisture supply and drought (rainfed) yicld was non-significant. Widely adapted (stable) cultivars (i.e.cultivars which are considered welladaptedio variation in moisture supply, in $1986 / 87$ and $1987 / 88$ were those with high mean yield, high rainfed yields and high yield potential; and in $1988 / 89$ when the rise in temperature in spring was fast, additional requirements for wide adaplation were early phenology and high harvest index. Chickpea cultivars with wide adaptation had deep root systems and high pre-dawn leaf water potential.

\section{INTRODUCTION}

In the Mediterranean basin of West Asia and North Africa (WANA), rainfall occurs in winter when temperatures are low (Kassam, 981 ; Smith and

Correspondence 10 (Presentaddress): S. N. Silim, International Crops Rescarch Institute for the Semi Arid Tropics (ICRISAT), P.O.BOX 39063, Nairobi, Kenya.

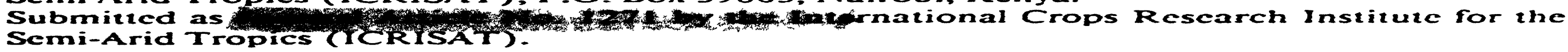

$0378-4290 / 93 / \$ 06.00$ (1993 Elsevier Science Publishers B.V. All rights reserved. 
Harris, 1981). From March onwards the region experiences increasing radiation and a rapid rise in temperature which reaches supra-optimal levels $\left(>32^{\circ} \mathrm{C}\right.$ ) during the May-June period (Cooper et al., 1987). Chickpea is an important grain legume crop of the rainfed farming systems of the Mediterranean basin. The cultivars commonly grown in WANA are unimproved $\mathrm{Ka}$ buli landraces (Saxena, 1985). They are usually grown in areas with mean annual rainfall of at least $400 \mathrm{~mm}$ (Keatinge and Cooper, 1983; Saxena, 1987), with large year-to-year fluctuations in amount, frequency and duration of rainfall. Spring chickpea is sown from the end of February to the beginning of March and thus grows mainly on stored soil moisture which is progressively depleted with crop growth. The crop experiences drought stress from the late vegetative stage until maturity. The intensity of drought stress varies from year to year, depending on the amount and distribution of rainfall and on spring temperatures.

At ICARDA (International Center for Agricultural Research in the Dry Areas), research emphasis in spring chickpea improvement is on the development of cultivars that give high and stable yields in environments where drought stress is one of the production constraints and on the ability of the crop to respond positively in wetter years. The line-source sprinkler irrigation system which supplies a decreasing gradient of water availability (Hanks et al., 1976) permits testing of the performance of cultivars under varying moisture supply but otherwise similar conditions of, for instance, temperature and soil depth which may in addition influence crop growth and yield.

The objectives of the three-year study reported here were to examine the response of spring-sown chickpea cultivars to variation in moisture supply and determine crop attributes associated with wide adaptation and develop breeding strategies that would incorporate traits responsible for wide adaptation.

\section{MATERIALS AND METHODS}

The study was conducted for three seasons, 1986/87, 1987/88 and 1988/ 89 , at ICARDA's main research station at Tel Hadya in northern Syria $\left(36^{\circ} 01^{\prime} \mathrm{N}, 36^{\circ} 56^{\prime} \mathrm{E}\right)$. The soil is Calcic Luvisol, highly calcareous and more than $2 \mathrm{~m}$ deep, with a field capacity of $44.6 \%$ and wilting point of $25.7 \%$. The chickpea lines used included landraces from WANA (Kabuli type) and the Indian sub-continent (Desi type), and high-yielding cultivars bred at ICARDA and ICRISAT (International Crops Research Institute for the Semi-Arid Tropics) in India. For convenience, the term cultivars is used to cover both cultivars and landraces. Sixteen, 17 and 20 chickpea cultivars were sown on 3 March 1987, 13 March 1988 and 26 February 1989, respectively. A basal dose of $22 \mathrm{~kg} \mathrm{P} / \mathrm{ha}$ was incorporated in the soil during land preparation. Seeds were sown in rows $0.3 \mathrm{~m}$ apart and $0.1 \mathrm{~m}$ within the row and inoculated with
Rhizobium to ensure good nodulation. A uniform irrigation with overhead sprinklers was given immediately after sowing if required to ensure complete emergence.

The experiment was laid out as a randomized block design with four replications. The plots were $3.6 \mathrm{~m}$ wide and $18 \mathrm{~m}$ long. A line-source sprinkler irrigation system was used to create a gradient of moisture supply. Areas close to the sprinklers received the highest supplemental moisture supply (nonstress and potential yield) and those farthest away, none (drought stress), the latter thus depending on rainfall only, which was stored in the soil profile. One line-source sprinkler irrigation system was installed between replicates 1 and 2 , and the second between replicates 3 and 4 . Irrigation was applied at dawn and only on windless days. The amount of water applied was measured in catch cans at $1,2,4,6,8,10,12$ and $14 \mathrm{~m}$ from the line-source sprinkler system.

Access tubes each $2.0 \mathrm{~m}$ deep were installed between rows in the rainfed (drought-stress) and non-stress ( $1.0 \mathrm{~m}$ from the line-source sprinkler) treatments. Soil moisture content was measured regularly at 0.15 -m intervals down the profile to $1.8 \mathrm{~m}$ with a neutron moderating soil-moisture meter (neutron probe, Wallingford Model 225), except for the top $0.15 \mathrm{~m}$ where it was determined gravimetrically. Soil water content and irrigation requirement in the non-stress treatment and seasonal evapotranspiration were calculated from the neutron probe data readings. It was intended that the deficit not exceed $40 \mathrm{~mm}$ in the non-stress treatment. This deficit was chosen as a probable level which does not affect most field crops (Penman, 1962). Effective rooting depth, i.e. greatest depth of water extraction by roots was derived from the neutron probe data.

Leaf water potential, an indicator of crop water deficit, was measured in the field at dawn using a portable pressure chamber (PMS Instruments, Royal Oaks, Oregon, USA).

Data were collected from rainfed (drought-stress) and non-stress treatments for the periods from sowing to $50 \%$ flowering and to maturity. At maturity, after discarding border areas, harvests were made for each cultivar at each moisture regime at seven (range 359-520 mm moisture supply), seven (range 504-634 mm) and nine (range 280-505 mm) levels of moisture supply, respectively, in 1986/87, 1987/88 and 1988/89. The net plot areas harvested varied from $4.5 \mathrm{~m}^{2}$ to $6.0 \mathrm{~m}^{2}$. The harvested plants were sun-dried to constant, very low moisture level, weighed, threshed and grain weight determined. Yield components were determined at harvest from separate $0.15-\mathrm{m}^{2}$ sub-samples from unirrigated and non-stress treatments.

No valid $F$-test exists for comparing the effect of variation in moisture supply on yield, because irrigation levels were systematically arranged in strip plots. The yield data were consequently analysed in two ways. Firstly, yield at each moisture level was analysed separately as a randomized block design. 
Secondly, a linear regression of yield of each cultivar on moisture supply was Jeveloped, and the differences in response to water supply across the irrigaion gradient were determined by comparing the regression slopes ( $b$ values), as described by Gomez and Gomez (1984).

\section{RESULTS AND DISCUSSION}

\section{Climate}

Details of the weather for Tel Hadya during the period of study are fully lescribed in Meteorological Reports for ICARDA Experiment Stations in Syria (ICARDA, 1988, 1989, 1990) and a summary is given in Figs. 1 and 2. The 1986/87 season was favourable for crop growth; precipitation was 359 $\mathrm{mm}$, slightly higher than the long-term average for Tel Hadya $(330 \mathrm{~mm})$, and

$$
50
$$$$
\text { 至 } 40
$$$$
20
$$$$
\text { 产 } 30
$$$$
\text { 递 } 20
$$

\section{- IrI ER}

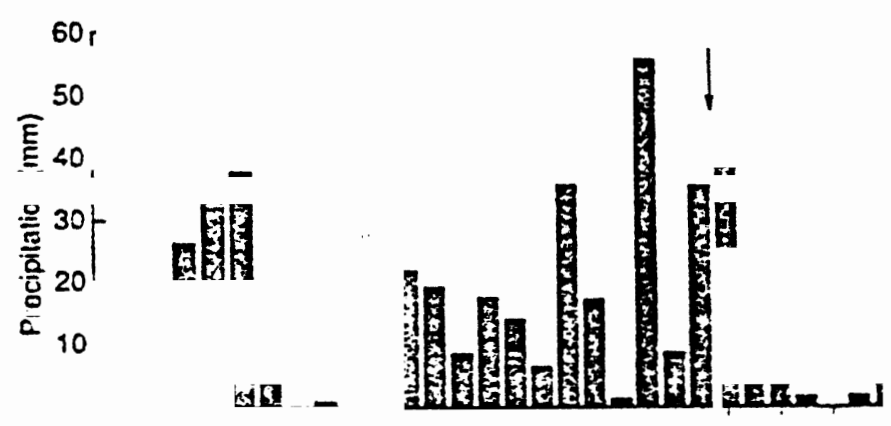

$60 r$
$1986 / 87$

\section{$1987 / 88$}

里

$1988 / 89$

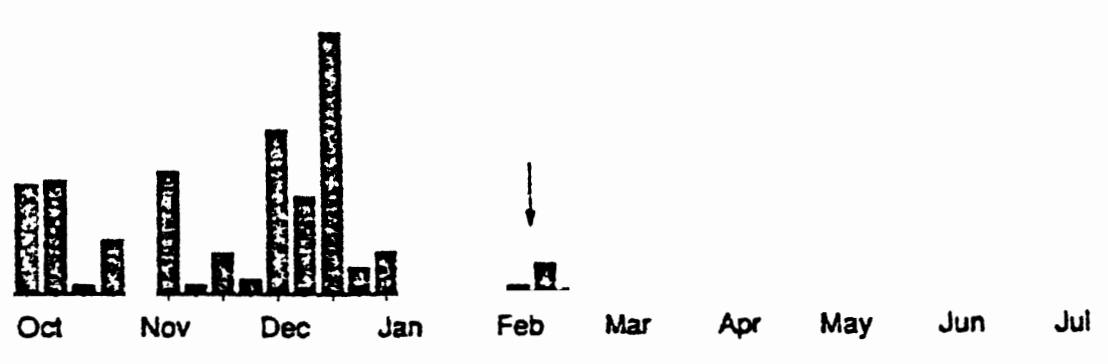

$$
\begin{aligned}
& \ldots . . .1986 / 87 \\
& --198788 \\
& \ldots . . .1988 / 89 \\
& - \text { Longterm average }
\end{aligned}
$$

30

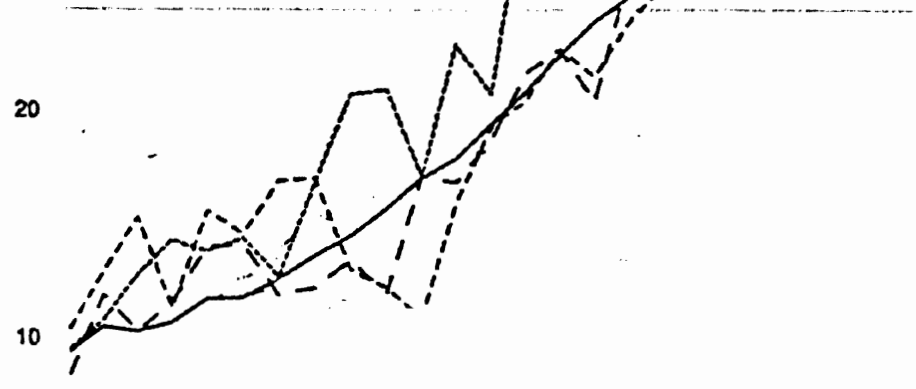

Mar
May Jun

Fig. 2. Mean weekly maximum temperatures at Tel Hadya during the January-June period in $1986 / 87,1987 / 88$ and $1988 / 89$.

the temperatures during the March-May period were lower than the longterm average, making it a low-stress season (for both drought and temperature) for spring-sown chickpea. The $1987 / 88$ season was again low-stress, precipitation was $504 \mathrm{~mm}$, the wettest since 1940/41, with temperatures similar to or slightly lower than the long-term average. The $1988 / 89$ season was an extremely high-stress season for spring-sown chickpea; total precipitation was only $234 \mathrm{~mm}$, with most received in the Novernber-January period, and the rise in temperatures was fast, with the March-May period experiencing higher temperatures than the long-term average.

\section{Effective rooting depth and leaf water potential}

The performance of spring-sown chickpea depends on the amount of moisture stored in the soil profile and the capacity of the root system to extract it. The depth of water extraction in the course of the season, representing effective rooting depth of some cultivars, is given in Fig. 3 for the 1988/89 season. The general pattern was similar for all chickpea cultivars, i.e. roots moved further down the soil profile as the season progressed. The greatest effective rooting depth, however, varied among the cultivars, with ILC 1919, ILC 1930, ICC 4958 and Annigeri extracting water at the greatest depths both under 
Days anter sowing

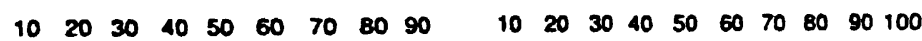

..
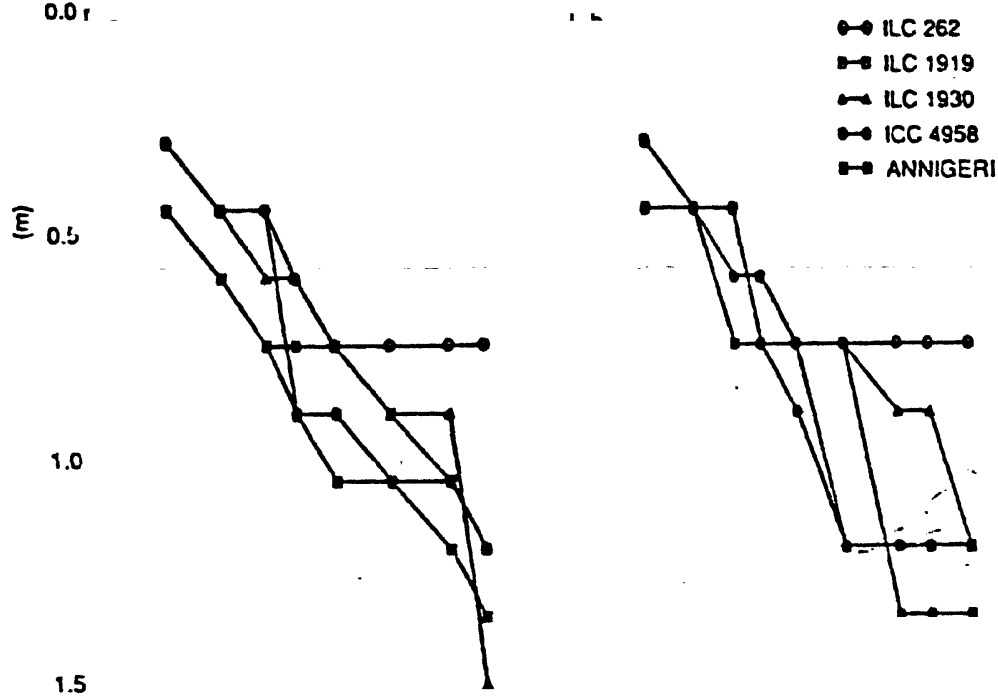

drought and irrigated conditions, suggesting that the trait 'deep root system' is expressed under both conditions and can thus be screened for under drought and non-drought conditions. The cultivars with deep root systems (Fig. 3) produced high grain yields in at least two out of the three years in the droughtstress treatment (Table 2), which is consistent with previous reports that in conditions where crops depend on residual moisture, deep rooting is advantageous (Lawn, 1988; Ludlow and Muchow, 1988; Gregory, 1989). Association between deep rooting and drought tolerance in chickpea was confirmed by Silim and Saxena (1993). The cultivar ILC 1930 had deep roots under both drought and irrigated conditions, but unlike other cultivars its roots were deeper under drought. In wheat, a similar trait is reported to favour yield under drought, and when water is not limiting, yield is even higher (Miglietta et al., 1987).

The time course of pre-dawn leaf water potential of some contrasting cultivars in the 1988/89 season is presented in Fig. 4. The cultivars ICC 4958 and Annigeri, with greater rooting depth (Fig. 3), had high leaf water potentials while ILC 262, with a shallower root system, had lower values, suggesting that the latter experienced greater stress. Under conditions where moisture is stored in the soil, pre-dawn water potential may be a suitable way of screening for deep root system.

Crop phenology

The range in number of day's from sowing to flowering was 53-84 in the $1986 / 87$ season with low temperatures, $45-59$ in the $1987 / 88$ season with high rainfall and 44-62 in the $1988 / 89$ high-stress season where rainfall was low and temperatures high; and the respective ranges in number of days from sowing to maturity were $87-101,75-96$ and $67-85$ in the drought treatment (Table 1). Both temperature and moisture supply during the growing period had a strong influence on phenology, with lower temperatures extending the time to flowering and to maturity. Similarly, time to maturity was extended by high moisture supply and reduced by drought. Irrigation extended reprodnztive growth. Cultivars from ICRISAT and India flowered first, foijowed by Kabuli types (with ILC numbers), and lines bred at ICARDA (FLIP numbers) (Table 1 ).

Yield, response to irrigation and yield components

The rainfed mean grain yields were higher in the low-stress seasons of 1986/ $87(0.984 \mathrm{t} / \mathrm{ha})$ and $1987 / 88(1.099 \mathrm{t} / \mathrm{ha})$ in contrast to a mean grain yield of only $0.187 \mathrm{t} /$ ha in the high-stress $1988 / 89$ season (Table 2). The range in the rainfed yields was from $0.636 \mathrm{t} / \mathrm{ha}$ in ICC 10448 to $1.231 \mathrm{t} / \mathrm{ha}$ in FLIP 83-2 in 1986/87, from $0.803 \mathrm{t}$ / ha in FLIP $85-4$ to $1.364 \mathrm{t} /$ ha in ILC 1930 in $1987 / 88$, and from $0 t /$ ha in ILC 100, FLIP 83-2, FLIP 84-80 and FLIP 85-4 to $0.658 \mathrm{t} / \mathrm{ha}$ in Annigeri in 1988/89 (Table 2). In each year, there were significant variations in grain yield among cultivars in the drought treatment. 
Number of days from sowing to nowering (FL) and maturity (MAT) in unirrigated (DR) and fully irrigated (IR) spring-sown chickpea at Tel Hadya, North Syria. in the 1986/87, 1987/88 and 1988/ 89 seasons

\begin{tabular}{|c|c|c|c|c|c|c|c|c|c|}
\hline \multirow[t]{3}{*}{ Cultivar } & \multicolumn{3}{|c|}{$1986 / 87$} & \multicolumn{3}{|c|}{$1987 / 88$} & \multicolumn{3}{|c|}{$1988 / 89$} \\
\hline & \multirow[b]{2}{*}{$\mathrm{FL}$} & \multicolumn{2}{|c|}{ MAT } & \multirow[b]{2}{*}{ FL } & \multicolumn{2}{|c|}{ MAT } & \multirow[b]{2}{*}{ FL } & \multicolumn{2}{|c|}{ MAT } \\
\hline & & $\mathrm{DR}$ & IR & & $\mathrm{DR}$ & IR & & DR & IR \\
\hline ILC 100 & NT & NT & NT & NT & NT & $N T$ & 57 & 80 & 96 \\
\hline ILC 262 & NT & NT & NT & NT & NT & NT & 52 & 77 & 95 \\
\hline ILC 464 & 68 & 97 & 109 & 51 & 86 & 93 & 56 & 80 & 96 \\
\hline ILC 624 & NT & NT & NT & NT & $N T$ & NT & 56 & 83 & 96 \\
\hline ILC 629 & 68 & 96 & 110 & 53 & 86 & 93 & 56 & 81 & 96 \\
\hline ILC 1272 & NT & $N T$ & NT & NT & $N T$ & NT & 51 & 77 & 95 \\
\hline ILC 1919 & 70 & 96 & 108 & 53 & 84 & 86 & 54 & 81 & 92 \\
\hline ILC 1929 & NT & $\Lambda T$ & NT & NT & $N T$ & $N T$ & 52 & 75 & 89 \\
\hline ILC 1930 & 68 & 96 & 108 & 50 & $\delta 2$ & $\delta 6$ & 56 & 80 & 92 \\
\hline FLIP $82-73$ & 70 & 100 & 110 & 53 & 89 & 93 & 57 & 80 & 96 \\
\hline FLIP 83-2 & 70 & 98 & 112 & 56 & 89 & 93 & 63 & 79 & 92 \\
\hline FLIP 84-12 & 71 & 99 & 114 & 56 & 92 & 96 & NT & NT & NT \\
\hline FLIP $84-74$ & 75 & 100 & 111 & 59 & 86 & 93 & NT & NT & NT \\
\hline FLIP $8 \div-78$ & 68 & 100 & 114 & 51 & 89 & 93 & $N T$ & NT & NT \\
\hline FLIP $84-80$ & 70 & 101 & 116 & 53 & 92 & 96 & 59 & 84 & 97 \\
\hline FLIP $85-4$ & 84 & 101 & 116 & 59 & 96 & 98 & 62 & 80 & 97 \\
\hline FLIP $85-49$ & 84. & 101 & 114 & 59 & 96 & 98 & 62 & 85 & 99 \\
\hline K 850 & NT & $\Lambda T$ & $N T$ & NT & $N T$ & $N T$ & 58 & 83 & 92 \\
\hline ICC 4958 & 65 & 95 & 106 & 49 & $\delta 2$ & 86 & 48 & 76 & 92 \\
\hline ICC $10+48^{2}$ & 70 & 96 & 108 & 53 & 86 & 93 & 56 & 79 & 89 \\
\hline ICC $10991^{\circ}$ & 69 & 97 & 109 & 52 & 86 & 93 & 53 & 79 & 92 \\
\hline ICCL $82001^{\circ}$ & 53 & 87 & 97 & 45 & 75 & 78 & 44 & 67 & 84 \\
\hline Annigeri" & NT & $N T$ & $N T$ & 51 & 89 & 93 & 51 & 76 & 92 \\
\hline Mean & 70 & 98 & 110 & 53 & 87 & 92 & 55 & 79 & 93 \\
\hline
\end{tabular}

Desi type from ICRISAT and 'Kabuli type from ICRIS.AT, India. The rest are all Kabuli type. FL are same in unirrigated and irrigated treatments.

NI $=$ not tested.

At the highest moisture supply, cultivars differed significantly in grain yield (Table 2). In all three years, ILC 1930 was amongst the highest yielding cultivars and ICC 4958 was in two out of three. These two cultivars also gave relatively high grain yields in rainfed conditions. Correlations between irrigated grain yield and days to flowering and maturity were positive, but not significant in 1986/87 and 1987/88, and negative and significant in 1988/89 (Table 3). Maximum temperatures in WANA rise rapidly in spring, reaching maxima exceeding the critical $30-32^{\circ} \mathrm{C}$ which can impose a limit on yield potential by hastening maturity (Harris, 1979). As shown in Fig. 2, in 1986/
Grain yield ( $\mathrm{t} / \mathrm{ha}$ ) of rainfed (drought yield) and fully irrigated (potential yield) chickpca cultivars sown at Tel Hadya, North Syria, during the 1986/87, 1987/88 and 1988/89 seasons

\begin{tabular}{|c|c|c|c|c|c|c|}
\hline \multirow[t]{2}{*}{ Cultivar } & \multicolumn{2}{|l|}{$1986 / 87$} & \multicolumn{2}{|l|}{$1987 / 88$} & \multicolumn{2}{|l|}{$1988 / 89$} \\
\hline & Unirrigated & Irrigated & Unirrigated & Irrigated & Unirrigated & Irrigated \\
\hline ILC 100 & NT & NT & NT & NT & 0 & 1.532 \\
\hline ILC 262 & NT & NT & $\mathrm{NT}$ & $N T$ & 0.395 & 2.252 \\
\hline ILC 464 & 1.078 & 2.196 & 1.255 & 1.908 & 0.027 & 1.474 \\
\hline ILC 624 & NT & 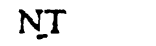 & NT & NT & 0.043 & 1.460 \\
\hline ILC 629 & 1.141 & 2.216 & 1.329 & 1.898 & 0.040 & 1.650 \\
\hline ILC 1272 & NT & NT & NT & NT & 0.172 & 2.041 \\
\hline ILC 1919 & 1.022 & 1.934 & 1.228 & 1.589 & 0.257 & 2.082 \\
\hline ILC 1929 & NT & NT & NT & NT & 0.195 & 2.093 \\
\hline ILC 1930 & 1.214 & 2.479 & 1.364 & 2.027 & 0.083 & 2.180 \\
\hline FLIP 82-73 & 1.046 & 1.983 & 1.160 & 1.633 & 0 & 1.480 \\
\hline FLIP 83-2 & 1.231 & 2.335 & 1.187 & 1.850 & 0 & 1.548 \\
\hline FLIP 84-12 & 1.025 & 2.353 & 1.017 & 1.851 & $N T$ & NT \\
\hline FLIP $84-74$ & 0.871 & 2.155 & 0.997 & 1.691 & NT & NT \\
\hline FLIP 84-78 & 0.927 & 2.070 & 1.269 & 1.929 & NT & NT \\
\hline FLIP $84-80$ & 1.143 & 2.186 & 1.061 & 1.895 & 0 & 1.453 \\
\hline FLIP 85-4 & 0.892 & 2.504 & 0.803 & 1.821 & 0 & 0.718 \\
\hline FLIP $85-49$ & 0.740 & 2.153 & 0.834 & 1.609 & 0.007 & 0.907 \\
\hline K 850 & NT & NT & $N T$ & NT & 0.085 & 2.098 \\
\hline ICC 4958 & 1.141 & 2.416 & 1.361 & 1.718 & 0.635 & 2.708 \\
\hline ICC 10448 & 0.636 & 1.285 & 0.861 & 1.140 & 0.205 & 1.678 \\
\hline ICC 10991 & 0.854 & 1.684 & 0.847 & 1.364 & 0.352 & 1.860 \\
\hline ICCL 82001 & 0.779 & 1.562 & 0.935 & 1.313 & 0.573 & 1.662 \\
\hline Annigeri & NT & $N T$ & 1.180 & 1.626 & 0.658 & 2.058 \\
\hline Grand mean & 0.984 & 2.094 & 1.099 & 1.851 & 0.187 & 1.749 \\
\hline Significance & $* * *$ & $* * *$ & $* * *$ & *** & $* * *$ & $* * *$ \\
\hline$S E \pm$ & 0.073 & 0.115 & 0.086 & 0.122 & 0.101 & 0.171 \\
\hline CV $(\%)$ & 12.9 & 9.5 & 15.6 & 14.3 & 18.2 & 19.5 \\
\hline
\end{tabular}

Significance: $* * *=P<0.001$.

NT $=$ Not tested.

87 temperatures for chickpea growth were favourable for an extended period and under such environmental conditions medium- to long-duration cultivars out-yield those of short duration. The 1988/89 season represents a North African type of environment where optimal cycle length is short and temperatures reach supra-optimal levels relatively early in the growing season. Therefore, even under assured moisture supply, high-yielding and better adapted cultivars would be short-duration types. The positive correlation between grain yield and biomass in 1986/87 and 1987/88 is consistent with the results of Silim et al. (1985) for peas and Silim and Saxena (1992) for faba bean, indicating that in favourable environments, the major factor associated 
Correlations of chickpea grain yield and some of the measured plant traits under irrigated conditions, Tel Hadya, Norhern Syria

\begin{tabular}{lccc}
\hline Traits & $1986 / 87$ & $1987 / 88$ & $1988 / 89$ \\
Days to flower & 0.345 & 0.130 & $-0.656^{* *}$ \\
Days to maturity & 0.449 & 0.195 & -0.432 \\
Biomass & $0.758^{* * *}$ & $0.827^{* * * *}$ & -0.302 \\
Harrest index & 0.229 & -0.022 & $0.810^{* * *}$ \\
Pods $/ \mathrm{m}^{2}$ & -0.356 & -0.192 & $-0.450^{*}$ \\
Seeds $/ \mathrm{m}^{2}$ & -0.402 & -0.185 & -0.381 \\
100-seed weight & $0.525^{*}$ & $0.549^{*}$ & 0.071 \\
\hline
\end{tabular}

Significance: ${ }^{*}=P<0.05 ;{ }^{* *}=P<0.01 ; * * *=P<0.001$.

TABLE 4

Linear regression parameters of response of grain yield to moisture supply (rainfall plus irrigation in $\mathrm{mm}$ ) in chickpea, Tel Hadya, North Syria, 1986/87

\begin{tabular}{lllll}
\hline Cultivar & $\begin{array}{l}\text { Intercept } \\
(\mathrm{t} / \mathrm{ha})\end{array}$ & $\begin{array}{l}\text { Slope } \\
(\mathrm{kg} / \mathrm{ha} / \mathrm{mm})\end{array}$ & $r$ & $\begin{array}{l}\text { Cultivar } \\
\text { mean vield } \\
(\mathrm{t} / \mathrm{ha})\end{array}$ \\
ILC 464 & -1.556 & 6.92 & & 1.58 \\
ILC 629 & -0.997 & 5.90 & 0.95 & 1.68 \\
ILC 1919 & -0.912 & 4.93 & 0.97 & 1.32 \\
ILC 1930 & -1.380 & 6.86 & 0.88 & 1.73 \\
FLIP 82-73 & -1.427 & 6.52 & 0.93 & 1.53 \\
FLIP 83-2 & -1.010 & 5.86 & 0.98 & 1.65 \\
FLIP 84-12 & -1.782 & 7.27 & 0.91 & 1.52 \\
FLIP 84-74 & -2.020 & 7.64 & 0.91 & 1.44 \\
FLIP 84-78 & -1.138 & 5.38 & 0.96 & 1.30 \\
FLIP 84-80 & -1.072 & 5.82 & 0.83 & 1.59 \\
FLIP 85-4 & -2.612 & 9.29 & 0.95 & 1.60 \\
FLIP 85-49 & -2.411 & 8.51 & 0.95 & 1.45 \\
ICC 4958 & -1.448 & 6.92 & 0.99 & 1.69 \\
ICC 10448 & -1.038 & 4.29 & 0.93 & 0.91 \\
ICC 10991 & -0.689 & 3.93 & 0.90 & 1.09 \\
ICCL 82001 & -0.943 & 4.60 & 0.92 & \\
Significance & $* * * 14$ & & 0.95 & \\
SE \pm & 0.215 & 0.470 & & \\
\hline
\end{tabular}

Significance: ${ }^{*}=P<0.05 ; * * * P<0.001$

with high grain yield is high biomass. Harvest index was positively and significantly correlated with grain yield only in 1988/89, which is in agreement with the report of Lawn (1988) that when the optimal growing period is short, a high harvest index is favoured and a main contributor of high grain yield.
Linear regression parameters of response of grain yield to moisture supply (rainfall plus irrigation in $\mathrm{mm}$ ) in chickpea, Tel Hadya, North Syria, 1987/88

\begin{tabular}{lllll}
\hline Cultivar & $\begin{array}{l}\text { Intercept } \\
(\mathrm{t} / \mathrm{ha})\end{array}$ & $\begin{array}{l}\text { Slope } \\
(\mathrm{kg} / \mathrm{ha} / \mathrm{mm})\end{array}$ & $r$ & $\begin{array}{l}\text { Cultivar } \\
\text { mean yield } \\
(\mathrm{l} / \mathrm{ha})\end{array}$ \\
\hline ILC 464 & -1.176 & 4.89 & 0.97 & 1.59 \\
ILC 629 & -2.322 & 6.54 & 0.94 & 1.37 \\
ILC 1919 & 0.201 & 2.15 & 0.95 & 1.42 \\
ILC 1930 & -1.171 & 4.98 & 0.98 & 1.64 \\
FLIP 82-73 & -1.478 & 5.09 & 0.95 & 1.40 \\
FLIP 83-2 & -0.564 & 3.42 & 0.99 & 1.37 \\
FLIP 84-12 & -2.546 & 7.04 & 0.98 & 1.43 \\
FLHP 84-74 & -1.912 & 5.75 & 0.98 & 1.34 \\
FLIP 84-78 & -1.441 & 5.31 & 0.99 & 1.56 \\
FLIP 84-80 & -2.381 & 6.85 & 0.97 & 1.49 \\
FLIP 85-4 & -3.369 & 8.19 & 0.98 & 1.26 \\
FLIP 85-49 & -2.112 & 5.85 & 0.99 & 1.20 \\
ICC 4958 & -0.060 & 2.99 & 0.90 & 1.58 \\
ICC 10448 & -0.285 & 2.67 & 0.83 & 1.00 \\
ICC 10991 & -1.265 & 4.10 & 0.98 & 1.05 \\
ICCL 82001 & -0.274 & 2.47 & 0.86 & 1.12 \\
Annigeri & -0.545 & 3.49 & 0.97 & 1.43 \\
Significance & - & & & \\
SE \pm & -0.230 & $* .406$ & & \\
\hline
\end{tabular}

Significance: $* * *=P<0.001$.

The positive correlation between irrigated grain yield and seed mass $(100$ seed weight) in two years out of three (Table 3 ) suggests that under favourable moisture and temperatures regimes, incorporating large-seededness further improves grain yield.

Tables 4-6 show positive and linear relationships between grain yieid and moisture supply for all cultivars. In all three years, grain yield response to moisture supply was explained best by linear regression and there were significant differences among the cultivars in response to moisture supply (slope, b) (Tables 2 and 4-6). In general, the cultivars that were most responsive to moisture supply had high yield potentials. The most responsive cultivars in the $1986 / 87$ season (FLIP $85-4$, FLIP $85-49$, FLIP $84-74$ and FLIP 84-12) and in the $1987 / 88$ season (FLIP 85-4, FLIP 84-12, FLIP 84-80, ILC 629 and FLIP 85-49) were generally medium to late flowering. This contrasts with the results of the dry 1988/89 season where cultivars of short to medium duration were generally most responsive to increased moisture supply (Tables 1,2 and 4-6).

Ceccarelli (1989), working with barley and Osmanzai et al. (1987) with 
Linear regression parameters of response of grain yield to moisture supply (rainfall plus irrigation in $\mathrm{mm}$ ) in chickpea, Tel Hadya, North Syria, $1988 / 89$

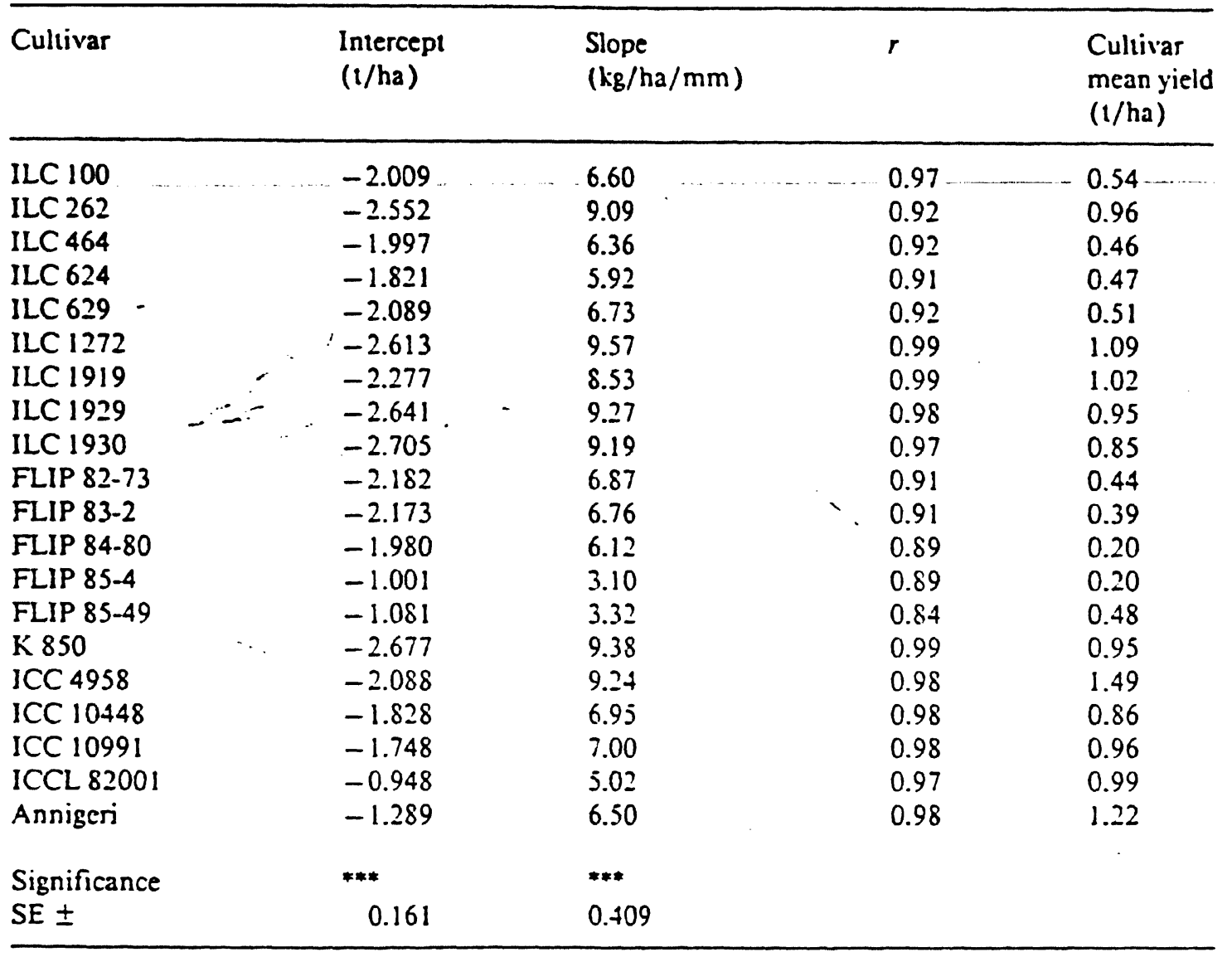

Significance: $* * *=P<0.001$.

wheat, suggested that the target environment must be defined when developing cultivars for wide adaptation. The target environment in this study is a region with winter rainfall, highly variable in amount and distribution, but with an annual mean of at least $400 \mathrm{~mm}$, and where temperatures rise fast after the cessation of rain. Spring-sown chickpea in this environment depends mainly on residual moisture. A cultivar with wide adaptation was described by Ceccarelli (1989) as one with high mean yield and low genotype (cultivar) $\times$ environment interaction (low b); and in lentil, Silim et al. (1993) defined stable desirable cultivars (cultivars with wide adaptation) as those with a high mean yield and an average (moderate) response to moisture supply. The results of the present study show that correlations between cultivar mean grain yield, rainfed (drought) grain yield and yield potential were highly significant and positive in all three years and those between cultivar mean grain yield and response slope to moisture supply $(b)$ were positive and significant in two years (Table 7 ). In addition, correlations between $b$ and yield poten-
TABLE 7

Correlations between days to flower, regression slope $(b)$, potential yield (irrigated yield), drought yield and cultivar mean yield (mean yield)

\begin{tabular}{lllll}
\hline Year and traits & DF & $b$ & POTYLD & DRYLD \\
\hline $1986 / 87$ & & & & \\
Days to nower (DF) & $0.701^{* *}$ & & & \\
Slope $(b)$ & 0.388 & $0.744^{* * *}$ & & \\
Potential yield (POTYLD) & -0.173 & 0.109 & $0.695^{* * *}$ & \\
Drought yield (DRYLD) & 0.221 & $0.633^{* *}$ & $0.931^{* * *}$ & $0.819^{* * *}$ \\
Mean yield (MYLD) & & & & \\
$1987 / 88$ & & & & \\
DF & $0.581^{*}$ & & & \\
$b$ & 0.182 & $0.585^{*}$ & & \\
POTYLD & -0.431 & -0.191 & $0.593^{*}$ & \\
DRYLD & -0.176 & 0.187 & $0.841^{* * *}$ & $0.831^{* * * *}$ \\
MYLD & & & & \\
$1988 / 89$ & & & & \\
DF & -0.385 & & & \\
$b$ & $-0.659^{* *}$ & $0.895^{* * *}$ & & $0.623^{* *}$ \\
POTYLD & $-0.842^{* * *}$ & 0.248 & \\
DRYLD & $-0.778^{* * *}$ & $0.639^{* *}$ & $0.855^{* * *}$ & $0.835^{* * *}$ \\
MYLD & &
\end{tabular}

Significance: ${ }^{*}=P<0.05 ;{ }^{* *}=P<0.01 ; * * *=P<0.001$

tial were strong and positive, but those between $b$ and rainfed yield were not significant. The latter could indicate that cultivars selected under favourable environmental conditions may not be widely adapted because high grain yield under those conditions may be due to either high $b$ or high rainfed yield. Similarly, selection based on high $b$ would favour cultivars with high yield potential and such cultivars may be susceptible to drought. For the WANA region, therefore, widely adapted desirable cultivars are those with high mean grain yield and high rainfed yield and, in addition, moderate response to moisture supply. Such cultivars for environments where moisture supply varies from moderate to high (1986/87 and 1987/88) are ILC 1930 and to a lesser degree ILC 464 and ILC 629; and for environments where variation in moisture supply includes very dry seasons (1988/89), cultivars such as ICC 4958 and Annigeri. These widely adapted cultivars appear to have deep roots and high predawn leaf water potential (Figs. 3 and 4 ).

Cumulative evapotranspiration ( $E J$ ) and water-use efficiency (WUE)

Cumulative evapotranspiration, also referred to as total water use, was computed from the neutron probe data for the rainfed and irrigated treatments and results for 1988/89 are presented in Table 8. In the rainfed treatment, the range in $E_{\imath}$ was small, from $133.2 \mathrm{~mm}$ in ICCL 82001 to $162.9 \mathrm{~mm}$ 
Total water use ( $E_{1}$ in $\mathrm{mm}$ ) and water-use efficiency (WUE in $\mathrm{kg}$ yield $/ \mathrm{mm} / \mathrm{ha}$ ) for grain yield (GY) and biomass (BY) of some chickpea cultivars grown rainfed (drought stress, $280 \mathrm{~mm}$ ) and with full irrigation (non-stress, $475 \mathrm{~mm}$ ) at Tel Hadya, in 19S8/89

\begin{tabular}{|c|c|c|c|c|c|c|}
\hline \multirow[t]{3}{*}{ Cultivar } & \multicolumn{3}{|c|}{ Rainfed (drought stress) } & \multicolumn{3}{|c|}{ Full irrigation (non-stress) } \\
\hline & \multirow[b]{2}{*}{$E_{\mathrm{i}}$} & \multicolumn{2}{|c|}{ WUE } & \multirow[b]{2}{*}{$E_{\mathrm{i}}$} & \multicolumn{2}{|c|}{ WUE } \\
\hline & & GY & $\mathrm{Br}^{\prime}$ & & GY & BY \\
\hline ILC 100 & 147.9 & 0 & 7.98 & 369.2 & 2.94 & 14.12 \\
\hline ILC 262 & 144.5 & 2.73 & 13.53 & 379.9 & 5.48 & 13.38 \\
\hline ILC 629 & 161.4 & 0.25 & 7.95 & 357.0 & 3.44 & 13.47 \\
\hline ILC 1272 & 158.0 & 1.09 & S. 48 & 352.2 & 5.84 & 14.58 \\
\hline ILC 1919 & 162.2 & 1.59 & 8.25 & 356.5 & 5.29 & 12.55 \\
\hline ILC 1929 & 158.1 & 1.11 & 6.41 & 369.6 & 5.26 & 12.85 \\
\hline ILC 1930 & 157.4 & 0.54 & 5.51 & 357.6 & 5.10 & 12.84 \\
\hline FLIP $82-73$ & 152.4 & 0.21 & 10.39 . & 373.6 & 3.67 & 14.07 \\
\hline FLIP 85-4 & 143.1 & 0 & 7.63 & 388.9 & 1.54 & 14.62 \\
\hline$k 850$ & 161.5 & 0.53 & 6.21 & 377.7 & 5.03 & 12.06 \\
\hline ICC 4958 & 154.3 & 4.12 & 8.49 & 333.1 & 7.41 & 14.07 \\
\hline ICC 10448 & 149.3 & 1.37 & 5.23 & 358.2 & 4.72 & 10.22 \\
\hline $1 C C L S 2001$ & 133.2 & 4.30 & 9.14 & 295.1 & 5.30 & 12.45 \\
\hline Annigeri & 162.9 & 4.04 & 7.91 & 3.48 .9 & 5.37 & 10.34 \\
\hline
\end{tabular}

in Annigeri. Water-use efficiency (WUE) in terms of grain yield under drought was high in early-flowering cultivars such as ICC 4958, ICCL 82001 and Annigeri (Tables 1 and 8 ). In terms of biomass, WUE did not show any consistent pattern, but some cultivars of medium to long duration showed high values. In the irrigated treatment the range in $E_{1}$ among cultivars was wide, varying from $295.1 \mathrm{~mm}$ in ICCL 82001 to $396.2 \mathrm{~mm}$ in ILC 100. Other cultivars with high $E_{1}$ values were FLIP 85-4, ILC $262, \mathrm{~K} 850$ and FLIP 82-73. In general, short-duration cultivars had low $E_{1}$, which is in agreement with results of Ludlow and Muchow (1988) who reported that potentially transpirable water may be left in the soil at maturity by early cultivars in favourable years and yield sacrificed as a consequence. For grain yield, WUE ranged from $1.54 \mathrm{~kg} / \mathrm{ha} / \mathrm{mm}$ water in FLIP $85-4$ to 7.41 in ICC 4958 and for biomass it ranged from $10.22 \mathrm{~kg} / \mathrm{ha} / \mathrm{mm}$ in Annigeri to $14.62 \mathrm{~kg} / \mathrm{ha} / \mathrm{mm}$ in FLIP 85-4 (Table 8).

\section{ACKNOWLEDGEMENT}

We would like to thank Dr K.B. Singh (ICARDA) and Dr N.P. Saxena (ICRISAT) for providing some of the seed used in this study, Drs F.R. Bidinger and $C$. Johansen for assistance in data analysis and suggestions during the writing of the manuscript. Technical assistance from $\mathrm{Mr}$ N. Trabulsi and staff of the Crop Physiology Unit of the Legume Program is gratefully acknowledged.

\section{REFERENCES}

Ceccarelli, S., 1989. Wide adaptation: How wide? Euphytica, 40: 197-205.

Cooper, P.J.M., Gregory, P.J., Tully, D. and Harris, H.C., 1987. Improving water use efficiency in rainfed farming systems of West Asia and Norh Africa. Exp. Agric., 23:113-158.

Gomez, K.A. and Gomez, A.A., i984. Statistical Procedures for Agricultural Research. John Wiley and Sons, New York, NY.

Gregory, P.J., 1989. The role of root charácteristics in moderating the effects of drought. In P.W.G. Baker (Editor), Drought Resistance in Cereals. Commonwealth Agricultural Bureaux (CAB), Wallingford, pp. 141-150.

Hanks, R.K., Keller, J., Rassmussen, V.P. and Wilson, D.G., 1976. Line-source sprinkler for continuous variable irrigation-crop production studies. Soil Sci. Soc. Am. J., 40: 426-429.

Harris, H.C., 1979. Some aspects of agroclimatology of West Asia and North Africa. In: G.C. Hawtin and G.J. Chancellor (Editors), Food Legume Improvement and Devclopment. International Development Research Centre, Ontau:a, pp. 7-14

ICARDA (International Center For Agricultural Research in the Dry Areas), 1988. Meteorological Reports for ICARDA Experiment Stations in Syria: 1986/87 Season. ICARDA Aleppo, Syria, pp. 35-41.

ICARDA (International Center For Agricultural Research in the Dry Areas), 1989. Meteorological Reports for ICARDA Experiment Stations in Syria: 1987/88 Season. IC.ARDA Aleppo, Syria, pp. 37-43.

ICARDA, 1990. Meteorological Reports for ICARDA Experiment Stations in Syria: 1988/89 Season. ICARDA, Aleppo, Syria, pp. 51-58.

Kassam, A.H., 1981. Climate, soil and land resources in North Africa and West Asia. In: J. Monteith and C. Webb (Editors), Soil, Water and Nitrogen in Mediterranean-type Environments. Martinus Nijhoff/Dr W. Junk Publishers, The Hague, Netherlands, pp. 1-29.

Keatinge, J.D.H. and Cooper, P.J.M., 1983. Kabuli chickpea as a winter-sown crop in northern Syria: Moisture relations and crop productivity. J. Agric. Sci. (Camb.), 100: 667-680.

Lawn, R.J., 1988. Breeding for improved plant performance in drought-prone environments. In: F.R. Bidinger azd C. Johansen (Editors), Drought Research Priorities for the Dryland Tropics. International Crops Research Institute for the Semi-Arid Tropics (ICRIS.AT), Patancheru, India, pp. 213-219.

Ludlow, M.M. and Muchow, R.C., 1988. Critical evaluation of the possibilities for modifying crops for high production per unit precipitation. In: F.R. Bidinger and C. Johansen (Editors) Droughi Research - Priorities for the Dryland Tropics. International Crops Research tors), Drought Research - Priorities for the Dryland Tropics. International Crops

Institute for the Semi-Arid Tropics (ICRISAT), Patancheru, India, pp. 179-211.
Miglictta, F., Vassana, C. and Porceddu, E., 1987. Agroecological models and wheat ideotypes for semi-arid lands. In: J.P. Srivastava, E. Porceddu, E. Acevedo and S. Varma (Editors), Drought Tolerance in Winter Cereals. John Wiley and Sons, Salisbury, pp. 15-35.

Osmanzai, M. Rajaram, S. and Knapp, E.B., 1987. Breeding for moisture-stressed areas. In: J.P. Srivastava, E Porceddu, E. Acevedo and S. Varma (Editors), Drought Tolerance in Winter Cereals. John Wiley and Sons, Salisbury, pp. 151-161.

Penman, H.L., 1962. Woburn irrigation. 11. Results for grass. Neth. J. Agric. Sci., 4: 9-29.

Saxena, M.C., 1985. Food legume improvement program al ICARDA - an overview. In: M.C. 
Saxena and S. Varma (Editors). Faba Beans, Chickpeas and Lentis in the I98Os. ICARDA. Aleppo.pp. 1-13.

Saxena. M. C. I987. Agronomy of chickpea. In: M.C. Saxena and K.B. Singh (Editors), The Chickpea CA 3 iniernational, vallingrora, pp. $207-232$.

Silim. SN and Saxena. M.C. 1992 . Comparaive performance of faba bean ( 1 icia faba) plant

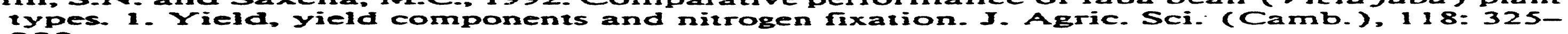

Silim, S.N. and Saxena, M.C., 1993 . Adapration or spring-sown chickpea to the Mediterranean basin. II. Fackors innuencing yield under drought. Field Crops Res.34: 37 - 46.

Silim, S.N., Hebblethwaire, P. and Heath, M.C., 1985 . Comparison of the errects of autumnand spring sowing date on growh and yield of combining peas (Pisum sarivuri). J. Agric. Sci. (Camb.). $104=35-46$.

Silim, S.M., Saxena, M.C. and Erskine, W., 1993 . Adapiation or lentil io the Mtediterranean

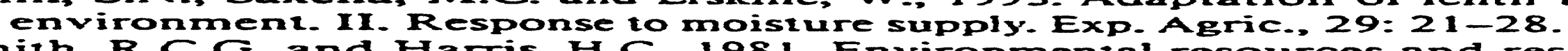

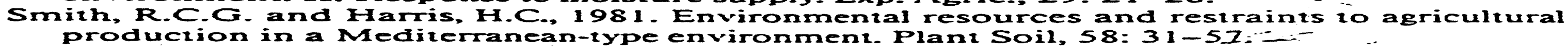

